\title{
LETTER
}

ACUTE LYMPHOBLASTIC LEUKEMIA

\section{Increased Incidence of IKZF1 deletions and IGH-CRLF2 translocations in B-ALL of Hispanic/Latino children-a novel health disparity}

\author{
Gordana Raca ${ }^{1}$ Hisham Abdel-Azim ${ }^{1} \cdot$ Feng Yue ${ }^{2}$ James Broach $\mathbb{1}^{2}$ - Jonathon L. Payne $\mathbb{C}^{3,2} \cdot$ Mark E. Reeves $^{3}$. \\ Chandrika Gowda $\mathbb{1}^{2} \cdot$ Joseph Schramm ${ }^{2}$. Dhimant Desai ${ }^{2} \cdot$ Elanora Dovat ${ }^{2} \cdot$ Tommy Hu$^{2} \cdot$ Arthur S. Berg $^{2} \cdot$ \\ Deepa Bhojwani $\mathbb{B}^{1} \cdot$ Kimberly J. Payne $\mathbb{B}^{3}$. Sinisa Dovat $\mathbb{D}^{2}$
}

Received: 26 September 2020 / Revised: 12 November 2020 / Accepted: 7 January 2021 / Published online: 2 February 2021

(c) The Author(s) 2021. This article is published with open access

\section{To the Editor:}

Hispanic/Latino (H/L) children and adolescents are 1.2-1.75 times more likely to develop acute lymphoblastic leukemia (ALL) than Non-Hispanic Whites (NHW) [1]. Once they develop ALL, H/L children have a $40 \%$ higher death-rate than NHW, after correcting for socioeconomic factors [2]. Although $\mathrm{H} / \mathrm{L}$ children with B-ALL have a worse prognosis than non-H/L children, the biological basis for this health disparity is largely unknown. Single nucleotide polymorphisms (SNPs) in ARID5B and GATA3 that are associated with predisposition to B-ALL and/or poor prognosis are more frequent among $\mathrm{H} / \mathrm{Ls}[3,4]$. However, the major drivers of B-ALL through which these SNPs might contribute to health disparities have not been defined.

A previous study of children with high-risk B-ALL showed increased incidence of $C R L F 2$ gene rearrangement in $\mathrm{H} / \mathrm{L}$ children as compared to the non-H/L population.

Supplementary information The online version contains supplementary material available at https://doi.org/10.1038/s41375021-01133-4.

Gordana Raca

graca@chla.usc.edu

$\triangle$ Kimberly J. Payne

kpayne@llu.edu

$\triangle$ Sinisa Dovat

sdovat@pennstatehealth.psu.edu

1 Childrens Hospital Los Angeles, University of Southern California Keck School of Medicine, Los Angeles, CA, USA

2 Pennsylvania State University College of Medicine, Hershey, PA, USA

3 Loma Linda University School of Medicine, Loma Linda, CA, USA
$C R L F 2$ gene rearrangement was also associated with deletion of the $I K Z F 1$ tumor suppressor [5]. A study of adult $\mathrm{H} / \mathrm{L}$ patients with $\mathrm{B}-\mathrm{ALL}$ showed increased incidence of Ph-like B-ALL that was associated with CRLF2 rearrangement and $I K Z F I$ deletion [6]. Both studies were limited to subsets of B-ALL patients with high-risk features. Thus, the question of whether $C R L F 2$ gene rearrangement and/or $I K Z F 1$ deletion provide a biological basis for the overall health disparity in pediatric B-ALL for $\mathrm{H} / \mathrm{L}$ children remains unanswered. Here, we address this question by performing a single-center, unbiased analysis to determine and compare the incidence of $C R L F 2$ rearrangement and $I K Z F 1$ deletion in $\mathrm{H} / \mathrm{L}$ vs. non-H/L children with B-ALL.

We analyzed clinical and molecular data [7] from 239 pediatric B-ALL patients treated at Childrens Hospital Los Angeles between 3/2016 and 7/2019 (See Supplemental Materials). Of 239 patients diagnosed with B-ALL, 164 self-reported as H/L and 75 were classified as non-H/L (Table 1). CRLF2 rearrangements include two types of genetic alterations: $I G H-C R L F 2$ translocation, where the immunoglobulin heavy chain locus $(I G H)$ is translocated to CRLF2 [8]; and P2RY8-CRLF2 fusion, where the PAR1 deletion juxtaposes the noncoding exon of $P 2 R Y 8$ to CRLF2 [9]. Analysis of each of these genetic alterations separately, showed significantly increased incidence of $I G H-C R L F 2$ translocation in the $\mathrm{H} / \mathrm{L}$ vs. non-H/L groups, $19 / 164(12 \%)$ vs. $2 / 75$ (2.7\%), $p=0.026$. However, the incidence of $P 2 R Y 8-C R L F 2$ fusion was not significantly different between the two populations.

B-ALL in the $\mathrm{H} / \mathrm{L}$ population showed a significantly higher incidence of $I K Z F 1$ deletion as compared to non-H/Ls, $48 / 164(29 \%)$ vs. $11 / 75(15 \%), p=0.016$. These results suggest that $I K Z F 1$ deletion is a novel biological determinant of the health disparity in pediatric B-ALL for H/L children.

Since the previous data suggested an association between $C R L F 2$ translocations and $I K Z F 1$ deletion, we analyzed the incidence of patients with concomitant $I K Z F I$ deletion and 
Table 1 Characteristics of B-ALL in Hispanic/Latino and Non-Hispanic/Latino children.

\begin{tabular}{|c|c|c|c|c|}
\hline Characteristic (all patients) & $\begin{array}{l}\text { Overall }^{\mathrm{a}} \\
N=239\end{array}$ & $\begin{array}{l}\text { Hispanic/Latino }^{\text {a }} \\
N=164\end{array}$ & $\begin{array}{l}\text { Non-H/L }{ }^{\mathrm{a}} \\
N=75\end{array}$ & $p$ value $^{\mathrm{b}}$ \\
\hline Age & $6.0(3.0,12.0)$ & $7.0(3.0,13.0)$ & $5.0(3.0,11.0)$ & 0.3 \\
\hline Gender & & & & 0.4 \\
\hline Female & $106(44 \%)$ & $76(46 \%)$ & $30(40 \%)$ & \\
\hline Male & $133(56 \%)$ & $88(54 \%)$ & $45(60 \%)$ & \\
\hline IKZF1 deletion & $59(25 \%)$ & $48(29 \%)$ & $11(15 \%)$ & 0.016 \\
\hline CRLF2 translocation (all) & $36(15 \%)$ & $28(17 \%)$ & $8(11 \%)$ & 0.2 \\
\hline$I G H-C R L F 2$ & $21(8.8 \%)$ & $19(12 \%)$ & $2(2.7 \%)$ & 0.026 \\
\hline$P 2 R Y 8-C R L F 2^{\mathrm{c}}$ & $15(6.3 \%)$ & $9(5.5 \%)$ & $6(8.0 \%)$ & 0.6 \\
\hline$I K Z F 1 \& C R L F 2$ & $20(8.4 \%)$ & $20(12 \%)$ & $0(0 \%)$ & $<0.001$ \\
\hline$I K Z F 1 \& I G H-C R L F 2$ & $18(7.5 \%)$ & $18(11 \%)$ & $0(0 \%)$ & 0.001 \\
\hline$I K Z F 1 \& P 2 R Y 8-C R L F 2$ & $2(0.8 \%)$ & $2(1.2 \%)$ & $0(0 \%)$ & $>0.9$ \\
\hline$I K Z F 1 \&$ no $I G H-C R L F 2$ & $41(17 \%)$ & $30(18 \%)$ & $11(15 \%)$ & 0.6 \\
\hline$I G H-C R L F 2 \&$ no IKZFI & $3(1.3 \%)$ & $1(0.6 \%)$ & $2(2.7 \%)$ & 0.2 \\
\hline$P 2 R Y 8-C R L F 2 \&$ no $I K Z F 1$ & $13(5.4 \%)$ & $7(4.3 \%)$ & $6(8.0 \%)$ & 0.2 \\
\hline $\mathrm{Ph}+\mathrm{ALL}$ & $12(5.0 \%)$ & $5(3.0 \%)$ & $7(9.3 \%)$ & 0.054 \\
\hline \multicolumn{5}{|l|}{ Children age $\geq 10$ only } \\
\hline Characteristic (Age $\geq 10)$ & $\begin{array}{l}\text { Overall }^{\mathrm{a}} \\
N=83\end{array}$ & $\begin{array}{l}\text { Hispanic/Latino } \\
N=59\end{array}$ & $\begin{array}{l}\text { Non-H/L }{ }^{\mathrm{a}} \\
N=24\end{array}$ & $p$ value $^{\mathrm{b}}$ \\
\hline Age & $15.00(11.00,17.00)$ & $14.00(11.50,17.00)$ & $15.00(11.00,17.00)$ & 0.8 \\
\hline Gender & & & & $>0.9$ \\
\hline Female & $34(41 \%)$ & $24(41 \%)$ & $10(42 \%)$ & \\
\hline Male & $49(59 \%)$ & $35(59 \%)$ & $14(58 \%)$ & \\
\hline$I K Z F 1$ deletion & $40(48 \%)$ & $35(59 \%)$ & $5(21 \%)$ & 0.002 \\
\hline CRLF2 translocation (all) & $21(25 \%)$ & $19(32 \%)$ & $2(8.3 \%)$ & 0.027 \\
\hline$I G H-C R L F 2$ & $18(22 \%)$ & $18(31 \%)$ & $0(0 \%)$ & 0.001 \\
\hline$P 2 R Y 8-C R L F 2$ & $3(3.6 \%)$ & $1(1.7 \%)$ & $2(8.3 \%)$ & 0.2 \\
\hline$I K Z F 1 \& C R L F 2$ & $19(23 \%)$ & $19(32 \%)$ & $0(0 \%)$ & $<0.001$ \\
\hline$I K Z F 1 \& I G H-C R L F 2$ & $18(22 \%)$ & $18(31 \%)$ & $0(0 \%)$ & 0.001 \\
\hline$I K Z F 1 \&$ \& $2 R Y 8-C R L F 2$ & $1(1.2 \%)$ & $1(1.7 \%)$ & $0(0 \%)$ & $>0.9$ \\
\hline$I K Z F 1 \&$ no $I G H-C R L F 2$ & $22(27 \%)$ & $17(29 \%)$ & $5(21 \%)$ & 0.6 \\
\hline$I G H-C R L F 2 \&$ no $I K Z F 1$ & $0(0 \%)$ & $0(0 \%)$ & $0(0 \%)$ & NA \\
\hline$P 2 R Y 8-C R L F 2 \&$ no $I K Z F 1$ & $2(2.4 \%)$ & $0(0 \%)$ & $2(8.3 \%)$ & 0.081 \\
\hline $\mathrm{Ph}+\mathrm{ALL}$ & $4(4.8 \%)$ & $2(3.4 \%)$ & $2(8.3 \%)$ & 0.6 \\
\hline
\end{tabular}

Bold values indicate statistical significance $p<0.05$.

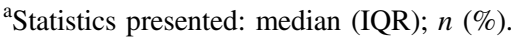

${ }^{\mathrm{b}}$ Statistical tests performed: Wilcoxon rank-sum test; Fisher's exact test.

${ }^{c}$ The P2RY8-CRLF2 translocation is more common in Down Syndrome B-ALL, the H/L cohort included three Down Syndrome cases (one $P 2 R Y 8-C R L F 2$ and two unknown genetics); the Other cohort included four Down Syndrome cases (three cases P2RY8-CRLF2, and one hyperploidy).
CRLF2 translocations. The concomitant IKZF1 deletion with either type (IGH-CRLF2 or P2RY8-CRLF2) of CRLF2 translocation was strongly increased in the H/L vs. non-H/L population, 20/164 (12.0\%) vs. 0/75 (0\%), $p<0.0001$. However, there was a strong bias in association of IKZFI deletion with a particular CRLF2 translocation; the $I g H-C R L F 2$ translocation was ninefold increased over the P2RY8-CRLF2 fusion (18/164 vs. 2/164) in patients with
$I K Z F 1$ deletion. As a consequence, IKZFI deletions concomitant with IGH-CRLF2 translocation were strongly increased in the H/L vs. non-H/L population, 18/164 (11\%) vs. $0 / 164(0 \%), p=0.001$. A concomitant $I K Z F 1$ deletion with $P 2 R Y 8-C R L F 2$ fusion was observed in only two patients, both in the $\mathrm{H} / \mathrm{L}$ population.

These data demonstrate that the $I G H-C R L F 2$ translocation, the $I K Z F 1$ deletion and the concomitant $I K Z F 1$ deletion with 


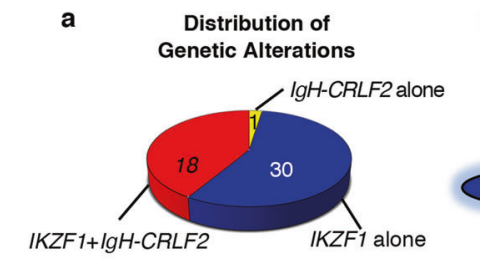

Fig. 1 IKZF1 Deletion IGH-CRLF2 Translocation in CRLF2 BALL of Hispanic Children. a Relationship between IKZF1 deletion and IGH-CRLF2 translocation in B-ALL of Hispanic/Latino children.

$I G H-C R L F 2$ translocation are highly increased in B-ALL of children in the $\mathrm{H} / \mathrm{L}$ population. The incidence of $P 2 R Y 8$ $C R L F 2$ fusion is not different between the two populations. IKZF1 deletion and IGH-CRLF2 translocation are each associated with poor prognosis [10-13] and both IKAROS and CRLF2 proteins regulate a large number of genes and/or pathways that promote leukemia progression and drug resistance $[14,15]$. Thus, these data provide evidence of $I G H$ $C R L F 2$ translocation and IKZF1 deletion as biological determinants of the health disparity in pediatric B-ALL for $\mathrm{H} /$ $\mathrm{L}$ patients and suggest a biological rationale for the inferior outcome of $\mathrm{H} / \mathrm{L}$ children with this disease.

We analyzed whether the age of patients affects the incidence, and/or racial difference of the above genetic alterations in B-ALL. In children $\geq 10$ yrs old (Table 1 ), the incidence of IKZF1 deletion is 2.8 -fold increased in the $\mathrm{H} / \mathrm{L}$ vs. non- $\mathrm{H} / \mathrm{L}$ population, $35 / 59(59 \%)$ vs. $5 / 24(21 \%), p=0.002$, with an odds ratio of 5.4. IKZFI deletion is highly increased in children $\geq 10$ yrs $(59 \%)$ vs. $<10$ yrs $(12 \%)$ in the $\mathrm{H} / \mathrm{L}$ population (Table S2), but not in the non-H/L group. In children $\geq 10 \mathrm{yrs}$, the incidence of $I G H-C R L F 2$ translocation was strongly increased in the $\mathrm{H} / \mathrm{L}$ vs. non-H/L population, $18 / 59$ (31\%) vs. $0 / 24(0 \%), p=0.001$. The incidence of IGH-CRLF2 translocation is highly increased in children $\geq 10 \mathrm{yrs}, 18 / 59$ (31\%) old vs. $<10 \mathrm{yrs}$ old, $1 / 105(1 \%)$ in the $\mathrm{H} / \mathrm{L}$ population, but not in the non-H/L group. All of the patients $\geq 10 \mathrm{yrs}$ with $I G H$ $C R L F 2$ translocations in both the $\mathrm{H} / \mathrm{L}$ and the non-H/L group also had concomitant $I K Z F 1$ deletions. Thus, no patient $\geq 10$ yrs had $I G H-C R L F 2$ translocation without concomitant $I K Z F 1$ deletion. In contrast, in patients $\geq 10 \mathrm{yrs}$ old, the IKZF1 deletion without the presence of the $I G H-C R L F 2$ translocation was detected in $17 / 59$ (29\%) of the H/L population.

In children $<10 \mathrm{yrs}$, neither $I G H-C R L F 2$ translocation, $I K Z F 1$ deletion, nor the combination of these two genetic alterations showed significant difference in incidence between the H/L and non-H/L populations (Table S1).

When analysis included only $\mathrm{Ph}$ negative B-ALL (Table S2-S4), the incidence of IKZF1 deletion was greater than threefold increased in the H/L vs. non-H/L population, $44 / 159(28 \%)$ vs. $6 / 68(8.8 \%), p=0.001$ and greater than fourfold increased in children $\geq 10 \mathrm{yrs}$ old, $33 / 57(58 \%)$ vs. $3 / 22(14 \%), p<0.001$.
The results of our study provide a biological rationale for the worse prognosis of B-ALL in $\mathrm{H} / \mathrm{L}$ children. Our unbiased, single-institution study identified highly increased incidence of $I G H-C R L F 2$ translocation, IKZF1 deletion and concomitant IGH-CRLF2 translocation with $I K Z F 1$ deletion in B-ALL of $\mathrm{H} / \mathrm{L}$ children. The approximate fourfold increased incidence in $\mathrm{H} / \mathrm{L}$ children with $\mathrm{B}-\mathrm{ALL}$, makes $I G H$-CRLF2 the single genetic alteration with the highest racial/ethnic pediatric cancer disparity. The very high overall incidence $(29 \%)$, makes $I K Z F 1$ deletion the most frequent genetic alteration that confers adverse prognosis in B-ALL in $\mathrm{H} / \mathrm{L}$ children. However, the largest difference between $\mathrm{H} / \mathrm{L}$ and non-H/L children was the presence of the concomitant IKZF1 deletion with $I G H-C R L F 2$ translocation, which was detected in $11 \%$ of $\mathrm{H} / \mathrm{L}$ children, but was not detected in any leukemia of non-H/L children.

The disparity in incidence of $I G H-C R L F 2$ translocation and $I K Z F I$ deletion in $\mathrm{H} / \mathrm{L}$ children vs. non-H/Ls was very strong in children $\geq 10 \mathrm{yrs}$, but not in younger children. The most intriguing finding in our study was that over 94\% (18/19) $\mathrm{B}-\mathrm{ALL}$ in $\mathrm{H} / \mathrm{L}$ children with $I G H-C R L F 2$ translocation had concomitant $I K Z F 1$ deletion. In contrast, $30 \mathrm{H} / \mathrm{L}$ children with B-ALL had IKZFI deletion without concomitant IGH-CRLF2 translocation. This raises the strong possibility that IKZFI deletion precedes $I G H-C R L F 2$ translocation, and/or that $I K Z F 1$ deletion predisposes cells to $I G H-C R L F 2$ translocation in B-ALL of H/L children. IKAROS represses transcription of the RAG1 gene and increased expression of RAG1 due to $I K Z F 1$ deletion, might play a role in this process (Fig. 1). The results of our study lead to two main questions: (1) What biological factors cause increased incidence of $I K Z F 1$ deletion in $\mathrm{H} / \mathrm{L}$ children; and (2) Does the presence of $I K Z F 1$ deletion in the B-lineage make cells more susceptible to the $I G H$ CRLF2 translocation, and if so, why is that susceptibility stronger in $\mathrm{H} / \mathrm{L}$ children than in non-H/L populations. One GATA3 SNP occurs at higher frequency in the $\mathrm{H} / \mathrm{L}$ population and has been associated with increased susceptibility to $C R L F 2$ rearrangement and $I K Z F 1$ deletion [3, 4]. However, functional studies to evaluate the potential role of GATA3 or non-H/L biological factors in CRLF2 and $I K Z F 1$ alterations have not been performed. Answering these questions will help in understanding the pathogenesis of pediatric B-ALL 
and the biological basis of the B-ALL health disparity in $\mathrm{H} / \mathrm{L}$ children.

In summary, the presented data demonstrate that $I G H$ $C R L F 2$ translocation and $I K Z F 1$ deletion provide a biological basis for the health disparity in pediatric B-ALL for $H / L$ children and a strong biological rationale for the higher deathrate they experience due to B-ALL. Our study suggests that, in addition to reducing socioeconomic inequities, the following changes in clinical practice would improve the prognosis of $\mathrm{H} / \mathrm{L}$ children with B-ALL: (1) due to the high incidence of $I G H-C R L F 2$ translocation and $I K Z F 1$ deletion, every child of $\mathrm{H} / \mathrm{L}$ background with B-ALL should be tested specifically for the presence of both of these genetic alterations; and (2) novel treatment strategies that restore IKAROS function while targeting CRLF2 signaling pathways (e.g., JAK/STAT or PI3K/ AKT/mTOR), should be developed and clinically tested to reduce the health disparity in pediatric B-ALL.

Acknowledgements This work was supported by R01CA209829 (KJP and SD), R01CA213912 (SD), F30CA221109 (JLP); NCATS KL2TR002015 (CG); and the Four Diamonds Fund (SD).

Author contributions SD and KJP analyzed and interpreted data, wrote the paper and designed research: GR and HA collected data, analyzed and interpreted data, and wrote the paper; FY, JB, JLP, CG, $\mathrm{DB}$, JS, DD, ED, and TH analyzed and interpreted data; ASB performed statistical analysis; MER provided critical review and assisted in writing the paper.

\section{Compliance with ethical standards}

Conflict of interest The authors declare that they have no conflict of interest.

Publisher's note Springer Nature remains neutral with regard to jurisdictional claims in published maps and institutional affiliations.

Open Access This article is licensed under a Creative Commons Attribution 4.0 International License, which permits use, sharing, adaptation, distribution and reproduction in any medium or format, as long as you give appropriate credit to the original author(s) and the source, provide a link to the Creative Commons license, and indicate if changes were made. The images or other third party material in this article are included in the article's Creative Commons license, unless indicated otherwise in a credit line to the material. If material is not included in the article's Creative Commons license and your intended use is not permitted by statutory regulation or exceeds the permitted use, you will need to obtain permission directly from the copyright holder. To view a copy of this license, visit http://creativecommons. org/licenses/by/4.0/.

\section{References}

1. American Cancer Society. Cancer Facts and Figures for Hispanics/Latinos 2018-20. https://www.cancer.org/content/dam/ca ncer-org/research/cancer-facts-and-statistics/cancer-facts-andfigures-for-hispanics-and-latinos/cancer-facts-and-figures-forhispanics-and-latinos-2018-.pdf

2. Kehm RD, Spector LG, Poynter JN, Vock DM, Altekruse SF, Osypuk TL. Does socioeconomic status account for racial and ethnic disparities in childhood cancer survival? Cancer. 2018;124 (Oct):4090-7.

3. Xu H, Cheng C, Devidas M, Pei D, Fan Y, Yang W, et al. ARID5B genetic polymorphisms contribute to racial disparities in the incidence and treatment outcome of childhood acute lymphoblastic leukemia. J Clin Oncol. 2012;30 (Mar):751-7.

4. Perez-Andreu V, Roberts KG, Harvey RC, Yang W, Cheng C, Pei $\mathrm{D}$, et al. Inherited GATA3 variants are associated with Ph-like childhood acute lymphoblastic leukemia and risk of relapse. Nat Genet. 2013;45(Dec):1494-8.

5. Harvey RC, Mullighan CG, Chen IM, Wharton W, Mikhail FM, Carroll AJ, et al. Rearrangement of CRLF2 is associated with mutation of JAK kinases, alteration of IKZF1, Hispanic/Latino ethnicity, and a poor outcome in pediatric B-progenitor acute lymphoblastic leukemia. Blood. 2010;115(Jul):5312-21.

6. Jain N, Roberts KG, Jabbour E, Patel K, Eterovic AK, Chen K, et al. Ph-like acute lymphoblastic leukemia: a high-risk subtype in adults. Blood. 2017;129(Feb):572-81.

7. Hiemenz MC, Ostrow DG, Busse TM, Buckley J, Maglinte DT, Bootwalla M, et al. OncoKids: a Comprehensive Next-Generation Sequencing Panel for Pediatric Malignancies. J Mol Diagn. 2018;20(Nov):765-76.

8. Russell LJ, Capasso M, Vater I, Akasaka T, Bernard OA, Calasanz MJ, et al. Deregulated expression of cytokine receptor gene, CRLF2, is involved in lymphoid transformation in B-cell precursor acute lymphoblastic leukemia. Blood. 2009;114 (Sep):2688-98.

9. Mullighan CG, Collins-Underwood JR, Phillips LA, Loudin MG, Liu W, Zhang J, et al. Rearrangement of CRLF2 in B-progenitorand Down syndrome-associated acute lymphoblastic leukemia. Nat Genet. 2009;41(Nov):1243-6.

10. Moorman AV, Schwab C, Ensor HM, Russell LJ, Morrison H, Jones L, et al. IGH@ translocations, CRLF2 deregulation, and microdeletions in adolescents and adults with acute lymphoblastic leukemia. J Clin Oncol. 2012;30(Sep):3100-8.

11. Chen IM, Harvey RC, Mullighan CG, Gastier-Foster J, Wharton W, Kang H, et al. Outcome modeling with CRLF2, IKZF1, JAK, and minimal residual disease in pediatric acute lymphoblastic leukemia: a Children's Oncology Group study. Blood. 2012;119 (Apr):3512-22.

12. Mullighan CG, Su X, Zhang J, Radtke I, Phillips LA, Miller CB, et al. Deletion of IKZF1 and prognosis in acute lymphoblastic leukemia. N Engl J Med. 2009;360(Jan):470-80.

13. Kuiper RP, Waanders E, van der Velden VH, van Reijmersdal SV, Venkatachalam R, Scheijen B, et al. IKZF1 deletions predict relapse in uniformly treated pediatric precursor B-ALL. Leukemia. 2010;24(Jul):1258-64.

14. Ding Y, Zhang B, Payne JL, Song C, Ge Z, Gowda C, et al. Ikaros tumor suppressor function includes induction of active enhancers and super-enhancers along with pioneering activity. Leukemia. 2019;33(Nov):2720-31.

15. Song C, Ge Z, Ding Y, Tan BH, Desai D, Gowda K, et al. IKAROS and CK2 regulate expression of BCL-XL and chemosensitivity inhigh-risk B-cell acute lymphoblastic leukemia. Blood. 2020;136:1520-34. 